\title{
A SPATIO-TEMPORAL ANALYSIS OF DENGUE FEVER TRANSMISSION IN YOGYAKARTA CITY, INDONESIA
}

Sulistyawati ${ }^{1,3)}$,Fardhiasih Dwi Astuti ${ }^{1)}$, Sitti Rahmah Umniati²), Tri Baskoro Tunggul Satoto'), Joacim Rocklov3), Asa Holmner3,4)

1) Faculty of Public Health, Ahmad Dahlan University, Indonesia

2) Departments of Parasitology, Faculty of Medicine,

Gadjah Mada University, Indonesia; 3) Department of

Public Health and Clinical Medicine, Umea University, Sweden

4) Department of Radiation Sciences/ Biomedical Engineering,

Umea University, Sweden

\begin{abstract}
BACKGROUND: Dengue fever remains a major health problem in tropical countries. Some measures had been implemented by the government to control this disease. Apparently, however, these measures were not effective. Therefore, there is a need for a study that provides information to aid the control program. This study aimed at investigating the space-time clustering of dengue fever transmission in Yogyakarta.

SUBJECT AND METHODS: This was a retrospective cohort study using surveillance data on dengue fever cases in all subdistricts, Yogyakarta, Indonesia, from January to July 2014. This secondary data was obtained from the Municipality Health Office, Yogyakarta City. The space-time clustering of dengue fever case transmission was analyzed using SaTScan permutation model.

RESULT: Dengue fever case transmission was clustered temporarily in several spots during the study period. The clustering of dengue fever transmission differed significantly among sub-districts with Mergangsan sub-district showing the highest cluster $(\mathrm{p}=0.005)$.

CONCLUSION: There is a significant difference in dengue fever transmission clustering among sub-districts in Yogyakarta City with the highest cluster occurring in Mergangsan sub-district. This finding can be used to guide future study into intervention priority of dengue fever control in Yogyakarta City.
\end{abstract}

Keywords: dengue fever, cluster, space-time analysis, urban, SaTScan 